\title{
DE ORFEO A ORFEO. MITO Y EXÉGESIS EN EL TEATRO DE LOPE Y CALDERÓN
}

\author{
Juan Antonio Martínez Berbel \\ Depto. de Filologías Hispánica y Clásicas \\ Edificio de Filología \\ C/ San José de Calasanz, 33 \\ 26004 Logroño. La Rioja. España \\ juan.berbel@unirioja.es
}

No trataré en el presente trabajo de establecer ningún vínculo entre las obras lopesca y calderonianas dedicadas al mito de Orfeo en términos de inspiración y dependencia entre sí. Trataré, más bien, de explorar las diferentes vías de interpretación y los diferentes cauces genéricos que un mismo tema puede inspirar a dos autores dando lugar a producciones de muy diferente signo. El alcance y significación de las dos propuestas dramáticas sobre Orfeo (El marido más firme lopesco y El divino Orfeo calderoniano, que elevaría las propuestas a tres, teniendo en cuenta que son dos autos bastante alejados en diversos sentidos) y, obviamente, el género, condicionaron de manera decisiva, a mi entender, incluso las fuentes consultadas por ambos autores. Del mismo modo el condicionante genérico también es definitivo para 
plantear las interpretaciones como absolutamente diversas. Baste, como ejemplo, hacer una somera aproximación a las posibles fuentes de ambos autores. En Lope es más sencillo hacer una vinculación expresa con sus fuentes, porque su relato del mito está más cercano a la historia mítica transmitida desde sus fuentes grecolatinas ${ }^{1}$. Pero diferentes exégesis condicionan el repertorio de fuentes. En el caso de Calderón la finalidad es propedéutica y eucarística. La precisión «histórica» es irrelevante y, por consiguiente, el intento de localizar fuentes concretas se vuelve baldío, toda vez que a Calderón no le hace falta. Podría decirse que la materia mítica con la que Calderón construye sus obras podía provenir del propio conocimiento previo del autor, ya que tanto para él como para sus espectadores la historia de Orfeo, como tantas otras historias mitológicas, pertenecían a lo que podría llamarse imaginario colectivo, alimentado por textos literarios, pero también por paratextos, representaciones pictóricas, repertorios varios, enciclopedias, etc.

En definitiva, trataré, someramente, de referirme a las muy diferentes y múltiples posibilidades que el mito clásico tiene como cauce de expresión de conflictos, historias y motivaciones muy diferentes de aquellas existentes en la época en la que se gestó, desechando por ende intentos de filiación, inspiración o dependencias de obras ajenas.

Es el mito, por tanto, el principal protagonista de este trabajo.

\section{ORFEO Y EL ORFISMO}

Puede resultar redundante narrar en un espacio como este el desarrollo de un mito como el de Orfeo, toda vez que, amén de ser suficientemente conocido, puede ser consultado en múltiples lugares. La historia del héroe tracio que, habiendo perdido a su amada Eurídice a causa de la agresión de un pretendiente, Aristeo, decide bajar a los infiernos a buscarla y consigue convencer a los dioses del inframundo de que se la devuelvan pertenece, o debería pertenecer, también a nuestro imaginario colectivo. Como lo es también la impaciencia del enamorado (por volverse a mirarla mientras retornan ambos a la su-

${ }^{1}$ Ver Martínez Berbel, 2003, pp. 353 y ss. 
perficie, desoyendo de tal modo la condición impuesta para su recuperación) que provoca la pérdida definitiva.

Más interesante, a los efectos del desarrollo de este trabajo, me parece detenerse en aquellos aspectos que hacen de Orfeo un héroe particular. En efecto, Orfeo es un héroe diferente, no es como Perseo, Hércules o Jasón, tres de los más conocidos del universo mitológico grecolatino. Ni el combate, ni la hazaña o la gesta heroica lo caracterizan como a aquellos. Por lo pronto hay que reseñar que es un personaje que aparece poco en los relatos míticos, fuera de la historia de la que es protagonista. Además de en esta, Orfeo aparece únicamente, y de manera secundaria, en la aventura de los argonautas, si bien hay que aceptar que esta aparición secundaria también tiene su valor especial. Es el único que, con su canto, consigue contrarrestar el de las sirenas, que en realidad tienen un poder muy similar al suyo, el de la persuasión.

Curiosamente Calderón también recreó esta parte del mito de Orfeo en El divino Jasón, donde es alegoría de San Juan Bautista, y podría haber hecho lo mismo Lope en su Vellocino de oro, pero elimina a este personaje de su comedia, la más alejada, por cierto, de las fuentes de las comedias mitológicas que se conservan del autor madrileño.

Si seguimos a Carlos García Gual en su definición de héroe

Fueron los héroes «una raza más justa y más noble», genós diakaióteron kai áreion. No estaban dominados sólo por la violenta soberbia, la hybris, como los broncíneos, sino que se interesan por la justicia, dike, y eran mejores, áreioi, o incluso los mejores, áristoi, entre los humanos. Son sus representantes los héroes venerados del pueblo griego, esos que celebra la poesía épica, como los fieros reyes que combatieron en torno a Tebas y Troya, que suministraron materia de canto a los aedos como Homero ${ }^{2}$,

comprobamos inmediatamente que la definición no se compadece con el cantor tracio, pues en este no es ni su valentía, ni su fuerza fisica, ni su sentido de la justicia, ni su superioridad respecto a sus congéneres, lo que le hace héroe. Bien es cierto que Orfeo puede compartir en cierta medida alguna de las características anteriores, pero sus

${ }^{2}$ Ver García Gual, 1987, p. 75. 
atributos más significativos no son estos; son la técnica artística, el poder de convicción que de aquella se deriva y la lealtad al ser amado. Podría decirse que Orfeo es, casi, un antihéroe, sobre todo si atendemos a cómo se desarrolla su historia mítica hasta el final, en el que tiene que sufrir las iras de las mujeres tracias por su obstinación por mantener la fidelidad a su amada (y difunta Eurídice) y esto le provoca la muerte e incluso, según ciertas interpretaciones tardías, su vinculación con inclinaciones homosexuales e incluso pederastas. Pero nada de esto, obviamente, está en la recuperación barroca del mito, que sitúa el final del mismo en la (segunda) muerte de Eurídice y la pérdida definitiva para su amado.

Habría que reseñar que los héroes griegos, como los dioses, no son superiores moralmente a los humanos, al contrario de lo que estaríamos inclinados a pensar, y esto ya va marcando de manera muy especial el uso que le darán nuestras letras áureas a los mitos, cumpliéndose en muchas ocasiones la máxima de que un héroe grecolatino, al recrearse en el teatro áureo gana características de orden moral que no tenía en su origen. Estas características favorecieron su tempranísima cristianización, casi avant la lettre. La interpretación cristológica del mito, que es la que desarrolla Calderón, es anterior a su uso en autos sacramentales, muy anterior, de hecho. Y estas características particulares de Orfeo como héroe, de hecho, favorecieron este tipo de exégesis. Pierre Grimal pone especial énfasis en resaltar el carácter oscuro y fuertemente simbólico del mito de Orfeo, así como su antigüedad; pero quizá la característica que más nos interese para evaluar su transmisión en las letras áureas sea la de haberse convertido casi en una teología en sí misma, y la de haber provocado la aparición de numerosísimas obras literarias, muchas de ellas vinculadas con lo esotérico. El profesor francés afirma, de hecho, que elementos del mito de Orfeo están en la misma formación del cristianismo primitivo ${ }^{3}$. Entre los elementos que, sin duda, sirvieron a esa supuesta conformación del cristianismo primitivo y que, de manera concreta, sirven decididamente como facilitadores de su recuperación en las letras áureas, está el carácter redentor del héroe tracio,

${ }^{3}$ Ver Grimal, 1989, p. 391. 
su capacidad de salvar a los hombres ${ }^{4}$. Que Orfeo entrase al infierno estando vivo, y para salvar a un alma condenada, era el matiz que faltaba para que su adopción en el universo ideológico barroco se produjese sin excesiva dificultad. De hecho, no son pocos los autores que sacan a Orfeo del marco estricto de la mitología y lo convierten en referente cultural de la Grecia Clásica y Antigua, y por extensión, de la Europa Occidental. En torno a su figura nace un movimiento pseudofilosófico con muchas características de secta religiosa: el orfismo. Orfeo es un receptáculo, por así llamarlo, tremendamente polivalente ya desde el siglo II a.C., como bien resalta Enrique Duarte en su edición de las dos versiones del auto. Incluso antes se identifica con el monoteísmo. Si tenemos en cuenta que el mito, en su versión más completa, incluyendo por ejemplo a Eurídice y su muerte, como tema literario, no se desarrolla hasta época alejandrina (hacia el III a.C.), hay que reconocer una expansión más que veloz. Judíos de Alejandría así lo defienden en el ficticio Testamento de Orfeo. Texto que más tarde servirá como defensa de la nueva religión frente a las invectivas paganas. En él Orfeo reniega de lo enseñando hasta entonces y adopta las que serán las características del Dios judeocristiano. Hacia el siglo II el Protréptico de Clemente de Alejandría, contrasta ya las figuras de Cristo y Orfeo, negando su relación pero, de hecho admitiendo su penetración en las comunidades cristianas y en su imaginario. Curiosamente, el propio Calderón cita a este autor en el auto ${ }^{5}$. Que Orfeo se identificaba con Cristo muy tempranamente nos lo demuestran también opiniones como la de Orígenes, en su Contra Celso, donde defiende a la nueva Iglesia y ataca decididamente la identificación de Cristo con héroes paganos como Orfeo, o la de Eusebio de Cesarea, que también contrasta ambas figuras. Todos estos autores coinciden en admitir, aunque sea tácitamente, la relación existente, pero también en admitir la importancia de la música y el canto como elementos de seducción (que a Orfeo sirven para atraer a las bestias, pero no a los hombres, como puede hacer el Hijo del Hombre). La Edad Media, por su parte, mantendrá viva esta identificación. San Marcial, el himno «Morte

4 Mérito que comparte con un reducido número de divinidades o personajes míticos, entre ellos Museo, sanador y augur, Hesíodo, que transmite a los hombres las habilidades agrícolas u Homero, maestro en el arte bélico. Ver Jaeger, 1990, p. 342.

${ }^{5}$ Ver Calderón de la Barca, El divino Orfeo, pp. 318-319. 
Christi Celebrata», el Ovide Moralisé, bastante conocido, citado y estudiado, que incluye por primera vez la doble identificación OrfeoCristo y Eurídice-Eva (por la serpiente), el Ovide Moralisé en prose, el Ovidius Moralizatus de Bersuire (coetáneo y amigo de Petrarca) y una infinidad de versiones, traducciones y revisiones de todos ellos que llevan esta línea interpretativa hasta el mismo Renacimiento ${ }^{6}$.

\section{LA RECEPCIÓN Y LAS FUENTES}

En nuestro Siglo de Oro hay una profusión significativa de manuales, polianteas, mitografias y, en general, versiones de los mitos griegos que, de un modo u otro, sirvieron de libro de cabecera a nuestros dramaturgos para componer sus comedias de materia mitológica. Destacan por méritos propios tres autores, Jorge de Bustamante (Transformaciones de Ovidio, 1551), Juan Pérez de Moya (Filosofía secreta, 1585) y Baltasar de Vitoria (Teatro de los dioses de la gentilidad, 1620-1634). Los doce tratados que componen la obra de este último le confieren un carácter muy diferente a las dos primeras, traducciones, aunque contengan una importante parte exegética. La de Vitoria, por contra, dedica cada capítulo a un dios del panteón grecolatino, recogiendo información diversa en cada caso. Esta pudo ser una de las razones por las que las obras de Pérez de Moya y Bustamante sirvieran más frecuentemente como fuente de dramaturgos, ya que estarían más interesados en partir de una versión narrada de las historias míticas, fácilmente adaptables a las tablas ${ }^{7}$. Pese a que Lope prologó la obra del franciscano Vitoria y a que Calderón, con pocas dudas, lo manejó, es poco probable que fuera el tercero libro de consulta directa para componer fábulas. Los dos primeros, a mi entender, sí, desde luego en el caso de Lope sin muchas dudas. Jorge de Bustamante presenta una traducción que, aun siendo muy libre y versionada, es más literal que la de Pérez de Moya. No contiene, como la de este, ningún epígrafe ni capítulo explicativo de los mitos, más allá de comentarios internos. La versión de Pérez de Moya es, podría decirse, un manual específica-

${ }^{6}$ Una detallada exposición de la evolución de la figura de Orfeo hasta llegar al siglo XVII pueden encontrarse en Calderón de la Barca, El divino Orfeo, pp. 9-25 y en Duarte, 1997.

${ }^{7}$ Ver Martínez Berbel, 2003, pp. 29 y ss. 
mente diseñado para su consulta como tal, y pone especial énfasis, junto a la pequeña narración de cada mito, en una interpretación histórica (declaración) y una interpretación moral. Estamos lejos, en cualquier caso, de la alegorización completa presente en los autos de Calderón, aunque también de Lope, que huye completamente de alegorización alguna.

Si bien es cierto que, en tanto que el primero de los autores sirve de guía directa para la comedia lopesca ${ }^{8}$, la segunda de las fuentes, Pérez de Moya, sin ser alegórica, sí apunta elementos mucho más apropiados para la interpretación calderoniana:

-El sobrenombre de Sacro dado a Orfeo, obviamente inexistente en las fuentes ovidianas de Pérez de Moya, ni de ninguno de los mitógrafos renacentistas.

-El rechazo por parte del héroe de todo contacto con las mujeres tras su vuelta definitiva de los infiernos, y la eliminación de los pasajes en que se relata el acoso sufrido por parte de las mujeres tracias, la muerte del héroe a manos de estas y, obviamente, la interpretación que no pocas veces se hizo de que estos episodios eran una suerte de defensa de la homosexualidad.

- La presentación de Orfeo como sabio, en tanto que Eurídice encarna lo femenino en tanto que deseo y apetito sexual del que el hombre sabio debe protegerse, para no caer en el pecado.

- La virtud simbolizada en Aristeo, que se pierde por los apetitos carnales, como se pierden estos, o sea Eurídice. Orfeo bajará a los infiernos a por los que han caído en ellos por el pecado.

-En general los personajes masculinos giran en torno al polo de lo positivo y los femeninos al contrario.

-Eurídice, cae, peca, no se la describe como la sufridora de una afrenta, sino como pecadora y, por tanto, castigada.

En definitiva, la traducción del mito llevada a cabo por Pérez de Moya, aun no siendo alegórica, sí contiene elementos que se ajustan mucho mejor a la interpretación calderoniana que a la lopesca.

\footnotetext{
${ }^{8}$ Bustamante aumenta y modifica el mito original de Ovidio y Lope lo sigue sin percatarse de los añadidos del primero. Ver Martínez Berbel, 2003, pp. 387 y ss.
} 


\section{DOS GÉNEROS DIFERENTES}

Como he adelantado al principio del trabajo, los condicionantes genéricos son importantísimos a la hora de elegir una $\mathrm{u}$ otra interpretación por parte de los dramaturgos. De entre las variadas facetas que contienen los mitos clásicos, los dramaturgos áureos escogen aquellas que se adaptan mejor al tipo de obra en que van a insertarse. Paul Diel defiende la existencia de dos ámbitos fundamentales:

Los mitos, según su sentido oculto, tratan entonces dos temas: la causa primera de la vida (el tema metafísico) y el comportamiento sensato de la vida (el tema ético) ${ }^{9}$.

Las dos caras del mito de las que habla Diel bien podrían corresponderse con las dos recepciones diversas del mito en Calderón y Lope. De un modo conscientemente simplificado, ambas perspectivas ejemplifican dos líneas de interpretación muy delimitadas. Mientras que a Lope le preocupa el mito como cauce para expresar una determinada postura ante la vida, es la cuestión trascendente la que preocupa a Calderón. Es evidente que el género impone unas directrices, pero habría que preguntarse, para establecer el verdadero valor del elemento mítico para los autores, qué fue antes: la elección del género o la elección del mito. Sin atreverme a dar una respuesta categórica nos podría dar una pista de la respuesta el especial apego que tiene Calderón a utilizar los mitos en autos (Orfeo, Jasón, Prometeo, Perseo etc.) y la predilección de Lope por utilizar estos mismos mitos en comedias, no así en autos, de los que no se le conoce ninguno de ambientación mitológica.

Un último apunte, antes de referirme a las dos propuestas interpretativas merecería resaltar el hecho de que la presencia barroca de Orfeo no se limita a la literatura, ya que son numerosos los referentes artísticos que echan mano de este héroe en el contexto cultural áureo. Uno de los ámbitos privilegiados en este sentido es el de la pintura.

Orfeo, como bien indica José C. Agüera Ros, gozó de un gran éxito en tanto en el seiscientos como en el setecientos y fue una pauta

\footnotetext{
${ }^{9}$ Ver Diel, 1985, p. 21.
} 
inspiradora para numerosos artistas: pintores como Martínez del Mazo (yerno de Velázquez), Claudio Coello, Juan Bautista Maino, Acisclo Antonio Palomino, por citar sólo algunos, dedicaron cuadros, copiaron otros y, en definitiva, se insertaron en una corriente de recuperación y recreación de este mito en la que hay que contextualizar también las obras de Lope y Calderón. Afirma el citado autor que la razón de la extraordinaria difusión de este mito

fue seguramente el carácter y valor que el infortunado héroe adquirió como figura y alegoría, con posible equiparación a Cristo en lo mitológico. [...] En mayor medida proliferó entre los aficionados y poseedores de pinturas durante el siglo XVII, al ser uno de los asuntos principales en las preferencias temáticas de mitología y tanto para particulares laicos como eclesiásticos ${ }^{10}$.

Alude asimismo a la proliferación de arquitecturas con altares y figuras, para el Corpus y celebraciones eclesiásticas, ciertamente deteniéndose en detallar esta difusión en la Murcia del xvII, pero dando cuenta de una situación perfectamente extrapolable al resto de la España barroca. La interpretación en la que se insertará Calderón es, a tenor de los datos presentados, la que triunfa mayormente en la cultura áurea, a pesar de ser la propuesta lopesca más cercana a la literalidad del mito.

Si nos acercamos a las representaciones musicales del mito obtenemos resultados similares. Como afirma Armando López Castro ${ }^{11}$,

Hablar del teatro barroco es entrar de lleno en el mundo de la integración artística, participar del sueño de totalidad al que aspiran las distintas artes. Tal diálogo necesario aparece ya en Grecia, donde la poesía va acompañada de lira y la melodía expresa la unión de los pies poéticos del verso con los pies musicales de los cantos.

En Orfeo, mito donde la música tiene un valor intrínseco dentro de la narración, lo anterior tiene un valor doble, si se me permite, y vemos cómo Calderón nuevamente es el que culmina una tradición largamente asentada y tremendamente integradora de diferentes ver-

${ }^{10}$ Ver Agüera Ros, 2002, pp. 667-668.

${ }^{11}$ Ver López Castro, 2002, p. 813. 
tientes artísticas. Del aspecto musical del teatro del Calderón no me atreveré a hablar yo aquí demasiado, pues soy consciente de mis limitaciones en este campo, pero baste plantear que no son pocos los que consideran directamente estos dos autos (especialmente la versión de 1663) y otros muchos de Calderón como piezas, si no exclusivamente, sí fundamentalmente musicales. Sea como fuere, lo que es innegable es la estrechísima relación a que somete Calderón a los elementos dramático y musical en sus autos, consciente de que las posibilidades comunicativas de lo musical le permiten expresar con más precisión conceptos de elevada complejidad:

Para Calderón, la adecuación de la letra, del texto dramático, al carácter de la melodía, revela que la música es la reserva de sentido espiritual, que el discurso sonoro es más eficaz que el verbal para expresar los misterios divinos ${ }^{12}$.

\section{LOPE Y LA TRADICIÓN: ¿ALTERNATIVA?}

Tan extensa e intensa es la tradición simbólica del mito de Orfeo que casi podríamos llamar a la de Lope una tradición o interpretación alternativa. En tanto que comedia de corral, el público de El marido más firme no diferiría en lo sustancial del de El divino Orfeo, ya que la obra de Lope fue una de las pocas mitológicas no cortesanas. El público condiciona la exégesis: la carga moral de la obra, el tema del honor (y su peso), la configuración de los personajes, las tramas secundarias son tratadas de manera diferente en corte y corral, según el público receptor y el lugar.

Pero ya hemos reseñado antes que el propio héroe elegido es diferente y no responde a las características habituales del héroe grecolatino. La institución matrimonial, la fortaleza en el amor conyugal y la lealtad al ser amado son los cimientos sobre los que se asienta la construcción del Orfeo lopesco de El marido más firme. Este Orfeo, heredero de Bustamante, tiene determinados rasgos de relevancia, por su valor sociológico: era sabio, sagaz, gracioso y, muy importante, elocuente orador. Partiendo del retrato de Bustamante, Lope, asumiendo los anteriores rasgos en cierta medida, lo hace más contemporáneo,

${ }^{12}$ Ver López Castro, 2002, p. 814. 
más reconocible por los espectadores del corral; no sé si nuevo, pero al menos sí bastante modificado respecto a su original grecolatino. Como suele ocurrirle en otras ocasiones, Lope conserva los elementos externos del mito, pero modifica profundamente los internos, su significación y sus claves interpretativas.

Al tratarse de una comedia y sobre una trama posiblemente conocida por su público, el Fénix añade elementos y giros en la trama que no están ni en las fuentes originales, ni en las directas (fundamentalmente Bustamante). Añade un oráculo, que juega un papel importante en la técnica de anticipación o adelantamiento de las desgracias de Orfeo y Eurídice. Añade también un criado, obligado por las convenciones de la comedia, que es más juicioso que su propio amo. El propio personaje de Orfeo también se ve modificado en su carácter. Aunque, obviamente, sigue siendo músico no es esta su mayor fuerza, ni la condición de sabio que le había conferido una larga tradición medieval, de la que participa, por ejemplo Alfonso X El sabio. Jorge de Bustamante y Juan Pérez de Moya inciden en su carácter de sabio, docto, elocuente, juicioso, político, etc. El Orfeo de Lope es, ante todo, firme y fiel en su amor por Eurídice. La transformación llega al punto de no ya enmascarar las habilidades «tradicionales» del héroe, sino invertirlas. En la interpretación del Oráculo al que antes me refería será Fabio, el criado, el que se encargue de desentrañar su sentido recto, frente a la manifiesta ineficacia de su amo. De hecho, parece como si algunas de las habilidades del Orfeo clásico se hubiesen transferido a su criado.

No en vano, en manos del dramaturgo madrileño Orfeo tiene una función más limitada que en las versiones clásicas y más directa y sencilla: defender sin fisuras la institución del matrimonio.

Como hará Calderón después, Lope no respeta del mito más que su envoltorio exterior, e incluso rompe sin complejos el propio desarrollo narrativo del mismo. El mito de Orfeo es convenientemente modificado para plantear un conflicto humano que no existía en los orígenes.

La tradición de la fábula le interesa menos a Lope que centrar el conflicto dramático en torno a una cuestión de innegable actualidad: los celos y el matrimonio. Es cierto que las imposiciones genéricas de la comedia de corral ya incluían una preeminencia de la intriga dramática sobre los elementos espectaculares. Llama más la atención cuan- 
do este sistema se aplica a una comedia mitológica, con innegables posibilidades para el espectáculo escénico, pero Lope tiene claro que su interés fundamental es el hombre y a sus problemas y conflictos dedica todos los esfuerzos. El conflicto humano es el contenido que el dramaturgo reviste con unos ropajes fabulosos. Esta circunstancia tiene como consecuencia, por ejemplo, que el mito de Orfeo sea dotado de causalidad. Lope elimina el elemento azaroso, tan presente en la mitología grecolatina, y a cambio urde una trama de intrigas, condiciones, intereses y, especialmente, debilidades humanas que provocan la tragedia de los amantes. En las fábulas suele ser el hado, el azar, el fatum o bien el capricho divino lo que provoca la desgracia del hombre. En el teatro barroco es la propia debilidad humana, sus pulsiones, lo que lo llevan a su desgracia. Es una lucha del hombre contra sí mismo, contra sus debilidades. En este contexto, los responsables de esta trama en la comedia que nos ocupa, Aristeo y, secundariamente, Fabio, criado de Orfeo, se posicionan casi como personajes protagonistas en momentos puntuales, pero importantes, de la obra.

Orfeo, precisamente por esa resistencia a definirse con los cánones del héroe clásico, es perfecto molde para Lope a la hora de construir un conflicto a partir de las pulsiones humanas. Esta humanización es característica general de la interpretación mitológica lopesca, si bien hay que admitir que el proceso lo había ya iniciado Bustamante en su traducción de estas fábulas. Por ello encontramos que los elementos espectaculares, sobrenaturales, están muy disminuidos respecto de la fábula original, e incluso las referencias a las habilidades canoras de Orfeo bien pudieran considerarse parte de la hipérbole lírica inherente al texto literario. Incluso el descensus ad inferos está rodeado de una cierta apariencia de cotidianidad, de normalidad, despojándose el camino de las habituales descripciones detalladas de un ambiente sobrenatural.

Pudiéramos concluir que Lope se aleja del mito. No es así, en mi opinión, si hacemos una lectura reposada del espectáculo lopesco. Lejos de adulterar el mito original, el dramaturgo lo hace más contemporáneo, lo adapta a sus espectadores, pero mantiene su viveza, su capacidad de enfrentarse a la adversidad. Como ocurre con tantos otros héroes en manos de Lope, Orfeo es menos belicoso, menos arriesgado, menos valiente, pero más humano, más comprensible, en cierto 
modo es más heroico, aunque considerando un concepto diferente de héroe.

\section{Calderón Y la tradición Recta}

Como vengo adelantando desde el principio de este trabajo, la visión de Calderón es, obviamente, diferente de la de Lope. Decía Pedro León en un trabajo ya clásico sobre los dos autos que este autor se inserta en la interpretación moralizante medieval. Como hemos tenido oportunidad de ver es mucho más antiguo el origen de la tradición en que se inscribe Calderón para acercarse al mito de Orfeo ${ }^{13}$. Muchos eran los referentes que tenía don Pedro para componer su obra: desde las versiones más humanísticas de Poliziano (Orfeo, 1471), la ópera de Monteverdi en 1607 hasta la propia del Fénix (de hacia 1620), continuada en cierta manera por Jáuregui y Montalbán. Con ninguna de ellas se puede establecer una relación de dependencia, por la muy diferente tradición interpretativa que adopta Calderón.

La paradoja teológico-poética, que sitúa a un Aristeo (en el primero de los autos y sin tal nombre en el segundo) como Príncipe de las Tinieblas en una posición central de la trama, con un protagonismo casi principal, sigue la opinión de San Pablo, de que Dios y las cosas de Dios son pequeñas cuando en realidad son fuertes. La relativa fuerza de Aristeo (el Demonio) contrastará a la postre con la absoluta fuerza de Orfeo (Dios).

Si bien a partir de la edición de Duarte contamos con información sustancial de ambas versiones, la de 1634 y la de 1663, es cierto que es de esta última de la que disponemos de una mayor y más exhaustiva información.

La escenografía está más controlada, más ceñida, podríamos decir, los personajes responden a un engranaje perfectamente coordinado y la repetición como recurso retórico acompaña y afianza un sistema de discursos que transmiten un mensaje teológico claro y sin fisuras. El mito, en Calderón, cumple una función de "envase conceptual» perfecto. Es sólo lo externo lo que preocupa e interesa al dramaturgo, los 
lances que hagan más amenas unas enseñanzas que son anteriores (literal y literariamente) a la concepción de la obra dramática ${ }^{14}$.

En el auto de 1634, aun conteniéndose el mensaje teológico con igual firmeza, hay una mayor naturalidad en el tratamiento, cierta relajación formal que permite, por ejemplo, que junto a la historia de Orfeo, Aristeo y Eurídice, aparezcan por ahí las historias bíblicas de la creación, la caída del hombre y su redención. Aun con todo, de los Orfeo, Aristeo y Eurídice clásicos, prácticamente no queda nada.

Aristeo se ve rodeado de la parafernalia (e incluso la versificación de arte mayor, octavas, silvas) de un personaje noble y principal, en tanto que Orfeo, como pastor humilde, usa mayormente el romance como voz poética (recordemos aquí la paradoja de San Pablo). Hasta el final del auto el Orfeo pastor-cantor no se convertirá en OrfeoRedentor, mostrando su verdadera fuerza y protagonismo. Aristeo, por su parte, es el noble poderoso y ridículo, cuya fuerza, a la postre es puesta en solfa por el humilde pastor.

Pedro León se preguntaba en el trabajo antes aludido la razón por la que Calderón crearía un demonio tan grandioso, parecido por cierto al utilizado en El veneno y la triaca ${ }^{15}$. Entre las posibles respuestas, la de una cierta inexperiencia calderoniana en esa época para componer autos y la aplicación de la paradoja paulina, yo me inclino por la segunda: cuando más poderoso ese demonio, más valor supone su derrota.

Con todo, y aun sabiendo fingida una cierta simpatía del personaje de Aristeo, que no será más que una fachada de su maléfico interior, no es muy alejado de la positiva construcción del personaje que hace Lope, convirtiéndolo en galán.

De los cinco modos de interpretar la fábula de los que habla, por ejemplo, Juan Pérez de Moya en su Filosofía secreta ${ }^{16}$ (literal, alegórico, anagógico, tropológico y físico o natural) es el alegórico (o más bien el alegórico-místico) el elegido es este último en el caso calderoniano.

Al hablar del auto sacramental, en términos generales, Chapman afirma:

\footnotetext{
${ }^{14}$ Ver Calderón de la Barca, El divino Orfeo, pp. 66 y ss.

${ }^{15}$ Ver León, 1983, pp. 694-695.

16 Ver Pérez de Moya, Filosofía secreta.
} 
El auto es sacramental y la interpretación de la fábula se hace en términos teológicos. Esta es la diferencia esencial con la comedia. [...] La comedia se haya concebida en términos humanos; el auto en divinos ${ }^{17}$.

Este autor hace hincapié en que la alegoría de partida no cambia, siendo la diferencia el lugar donde residen los conflictos: el de la abstracción teológica para el auto o el de las pulsiones humanas, para la comedia.

Orfeo está representado de manera específica por sus habilidades canoras. Con independencia de la interpretación, es cierto que esta característica es muy apropiada para Calderón, preocupado de modo muy significativo por la dimensión musical de sus obras, de manera general y de manera específica en los autos de El divino Orfeo.

La fábula es un instrumento de exaltación del sacramento de la Eucaristía, en una acertada fusión de lo mítico y lo cristiano, donde el instrumento musical, la cítara, se convierte en elemento redentor. El argumento del mito clásico interesa poco o nada, lo único importante son los elementos referenciales que necesita el público. Elementos centrales como el intento de violación de Eurídice, la famosa condición de no volverse a mirarla al salir del infierno, son eliminados o sustituidos. Este último, en el auto de 1634 se sustituye por un parafraseo de la tentación de Eva (Eurídice) por parte de la serpiente (Aristeo).

La bajada a los infiernos, obviamente, es la Pasión y Muerte de Cristo, la salida del reino, la Resurrección.

Calderón, como no podía ser de otra manera, era consciente de la tradición en la que se insertaba, pues da cuenta de alguna de las posibles fuentes que a su vez lo son de la primitiva cristianización del mito (vv. 155-180):

Músico has sido excelente.

Canto es tu voz que publica

tu Amor y así en los cantares

lo entenderá, cuando diga

San Clemente Alejandrino,

${ }^{17}$ Ver Chapman, 1954, p. 58. 


\begin{abstract}
viendo que entiendes la cifra de la música del orbe, que eres maestro de capilla. [...]

la eterna Sabiduría

lo entiende así, cuando dice que con número y medida todo fue criado, como Crisóstomo nos lo explica. El instrumento templado eres tú y su melodía te ha de aplicar Agustino cuando sobre un rey salmista, con Ambrosio y Genebrardo, te llaman psalterio y cítara ${ }^{18}$.
\end{abstract}

En definitiva, la interpretación calderoniana aúna lo teológico, lo místico, lo litúrgico y lo bíblico y dota de una importancia capital al poder armonizador de la música. Pero por encima de todo ello, Calderón es consciente de formar parte de un universo interpretativo muy anterior a él, en el que se siente completamente a gusto y del que se convierte en uno de los eslabones más firmes en el siglo XVII.

\title{
A MODO DE CONCLUSIÓN
}

En manos de Lope de Vega y de Calderón de la Barca la humanización y la cristianización se configuran como dos modos de encarar la exégesis mítica, elegidos tanto por las preferencias particulares de los autores como por las imposiciones del género en que se vierte dicha exégesis. De un modo más preciso lo expresa el profesor López de Castro $^{19}$ :

Los mitos, de acuerdo con su sentido enigmático, se expresan en lenguaje simbólico. Conviene recordar que el mito de Orfeo, enraizado en una religión agraria que unía la vida y la muerte y sometido a constantes metamorfosis a lo largo del tiempo, presenta dos interpretaciones bá-

${ }^{18}$ Ver Calderón de la Barca, El divino Orfeo, pp. 318-319.

${ }^{19}$ Ver López Castro, 2002, p. 816. 
sicas: la pagana, desde Virgilio hasta Rilke, que nos ofrece una visión romántica del amante que fracasa frente a las fuerzas oscuras de la muerte; y la cristiana, en la que Orfeo, vencedor de Dionisio, se confunde con Jesús, vencedor de Satán.

Baste para terminar la conclusión, quizá apresurada sí es cierto, de que Lope elige la versión más pagana del mito, más cercana a Ovidio y Virgilio, aunque tamizada por los mitógrafos renacentistas, más humanística y más clásica.

Calderón, por su parte, supera esta visión dionisíaca, quizá trivial para sus más profundos intereses, y la cambia por la armonización apolínea, más trascendente, más seria.

Lo curioso es que estamos ante una batalla mítica eterna, la de lo dionisíaco, frente a lo apolíneo, que no sólo no se ha resuelto, sino que encuentra su razón de ser, precisamente, en su no resolución. 


\section{BiBLIOGRAFÍA}

Agüera Ros, J. C., «Abraham, Cristo y la Iglesia entre Orfeo, Baco, Medea y otras expresiones del Barroco efimero", en Calderón 2000. Homenaje a Kurt Reichenberger en su 80 cumpleaños, ed. I. Arellano, Kassel, Reichenberger, 2002, vol. II, pp. 662-680.

Bustamante, J. de, Las metamorfoses o transformaciones del muy excelente poeta

Ovidio, repartidas en quince libros, y traducidas en castellano, Amberes, Juan Steelsio, s. a., ¿1551?

Calderón de la Barca, P., El divino Orfeo, ed. E. Duarte, Kassel, Reichenberger, 1999.

Chapman, W. G., «Las comedias mitológicas de Calderón», Revista de Literatura, 5, 1954, pp. 35-67.

Diel, P., El simbolismo en la mitología griega, Barcelona, Labor, 1985.

DuArte, E., «El mito de Orfeo y su simbología cristológica en la tradición y en Calderón», en Divinas y humanas letras: doctrina y poesía en los Autos sacramentales de Calderón: actas del congreso internacional, ed. I. Arellano, J. M. Escudero, B. Oteiza y M. ${ }^{a}$ C. Pinillos, Kassel, Reichenberger, 1997, pp. 73-91.

García Gual, C., La mitología. Interpretaciones del pensamiento mítico, s. 1., Montesinos, 1987.

Grimal, P., Diccionario de mitología griega y romana, Barcelona, Paidos, 1989.

Jaeger, W., Paideia: los ideales de la cultura griega, México, Fondo de Cultura Económica, 1990.

LeÓn, P. R., "El divino Orfeo. Ca. 1634: paradoja teológico-poética», en Calderón, Actas del Congreso Internacional sobre Calderón y el teatro español del Siglo de Oro, ed. L. García Lorenzo, Madrid, Centro Superior de Investigaciones Científicas, 1983, vol. II, pp. 687-699.

López Castro, A., "Calderón y la expresión musical. A propósito del auto El divino Orfeo» en Calderón 2000. Homenaje a Kurt Reichenberger en su 80 cumpleaños, ed. I. Arellano, Kassel, Reichenberger, 2002, vol. II, pp. 813828.

Martínez Berbel, J. A., El mundo mitológico de Lope de Vega: siete comedias de inspiración ovidiana, Madrid, Fundación Universitaria Española, 2003.

Pérez de Moya, J., Filosofía secreta, ed. C. Clavería, Madrid, Cátedra, 1995.

Vitoria, Fray B. de, Teatro de los dioses de la gentilidad, Barcelona, Francisco Barnola, 1702, 2 vols. 